\title{
An Innovative Technique to select Angled Abutment using Inclination Gauge
}

\author{
${ }^{1}$ Anshul Mel, ${ }^{2}$ Gunjan Gupta, ${ }^{3}$ Varun Goyal
}

\begin{abstract}
It is appropriate to establish a balance between prosthetic and anatomical concerns when inserting an implant. If a clinician focuses on anatomical concerns, he or she may place the implant at an angle to avoid adjacent teeth or fenestrating the buccal or lingual bone plates. Then, to achieve prosthetically desired parallelism between implants or teeth, the clinician can place an angled abutment. Based on the limited clinical trials reported in the literature, angled abutments result in increased stress on the implants and adjacent bone, but within the physiological limit.

Numerous types of prefabricated abutments are available at specific angles. Preangled abutments with angulations varying from 15 to $35^{\circ}$ often are commercially available. Furthermore, laboratory technicians can fabricate custom abutments to contours needed for a satisfactory prosthetic reconstruction wherein we have to select proper angulations.
\end{abstract}

Keywords: Angled abutment, Implant system, Inclination gauge, Mandible.

How to cite this article: Mel A, Gupta G, Goyal V. An Innovative Technique to select Angled Abutment using Inclination Gauge. Int J Oral Implantol Clin Res 2016;7(2):25-29.

Source of support: Nil

Conflict of interest: None

\section{INTRODUCTION}

The success of dental implants has changed treatment planning for patients with edentulous areas dramatically. A critical determinant for placement of an implant is the height and width of bone available in the edentate sites. The clinician also needs to evaluate the angulation of the ridge before placing the implant. Ideally, implants should be placed parallel to each other and to adjacent teeth and be aligned vertically with axial forces. But, in some real

\footnotetext{
${ }^{1}$ Private Practitioner, ${ }^{2}$ Senior Resident, ${ }^{3}$ Reader

${ }^{1}$ Department of Prosthodontics, Aum Siddhy Prosthetic Care Surat, Gujarat, India

${ }^{2}$ Department of Prosthodontics, Post Graduate Institute of Medical Sciences, Rohtak, Haryana, India

${ }^{3}$ Department of Orthodontics, Sudha Rustagi College of Dental Sciences \& Research, Faridabad, Haryana, India

Corresponding Author: Gunjan Gupta, Senior Resident Department of Prosthodontics, Post Graduate Institute of Medical Sciences, Rohtak, Haryana, India, Phone: +91-8585902828 e-mail: aagunjangupta@gmail.com
}

clinical situations, severely resorbed bone may result in inappropriate implant alignment, which can cause disparities between the implant long axis and the abutment long axis. Under such circumstances, difficulties will be certainly encountered in future prosthesis fabrication. Two options are available to overcome such problems, the angled implant ${ }^{1}$ and the angled abutment. ${ }^{2}$ The results of several studies have suggested that angled abutments result in increased stress on supporting implants, adjacent bone, and the prostheses they support, but it should be within the physiological limits of bone. ${ }^{3}$ Numerous types of prefabricated abutments are available at specific angles. Custom-made or preangled abutments with angulations varying from 15 to $35^{\circ}$ are commercially available; we have to select the proper angulations so that the stresses generated by angled abutments are within physiological limits of bone. ${ }^{4}$

Here, we present an inclination gauge, which detects proper angulations to help select correct angulated abutment, which produces stress on bone within physiological limits, and, along with it, achieves parallelism between implants or adjacent structures.

\section{MATERIALS AND METHODS}

An inclination gauge has benefits that can be used in all conditions, such as single tooth missing (anterior and posterior), multiple tooth missing (anterior and posterior), and immediate placement and immediate loading. However, the limitation of this instrument is that it requires adjacent tooth as a guide to measure angulations.

Parts of instrument are occlusal table (Fig. 1), gauge analyzer (Fig. 1), gauge assembly with pointer (Fig. 1), hex for controlling gauge analyzer (Fig. 1), measuring protector (Fig. 1), hex for controlling gauge assembly (Fig. 1).

Occlusal table (Fig. 1A): It is used to place the cast of the patient. It is made up of 4-mm-thick clear acrylic resin sheet to provide strength and to make tripoding easy. It is " $U$ " shaped with length and breadth of $7 \mathrm{~cm}$ (same as dimension of bite fork provided with Hanau articulator). On this table, a " $\mathrm{U}$ "-shaped channel (Fig. 1B), which is $7 \mathrm{~mm}$ in width, is provided to place gauge assembly with pointer to position the cast with the implant. In that channel, three stoppers are provided to seat the cast on occlusal table. 


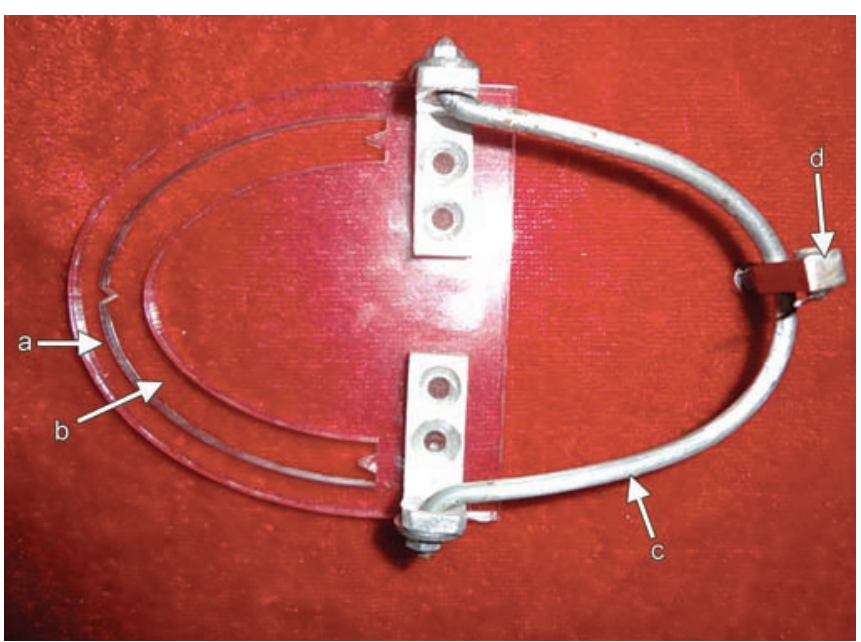

Fig. 1: Parts of inclination gauge: (A) Occlusal table; (B) U-shaped Channel in occlusal table; (C) Gauge analyser; and (D) Gauge assembly

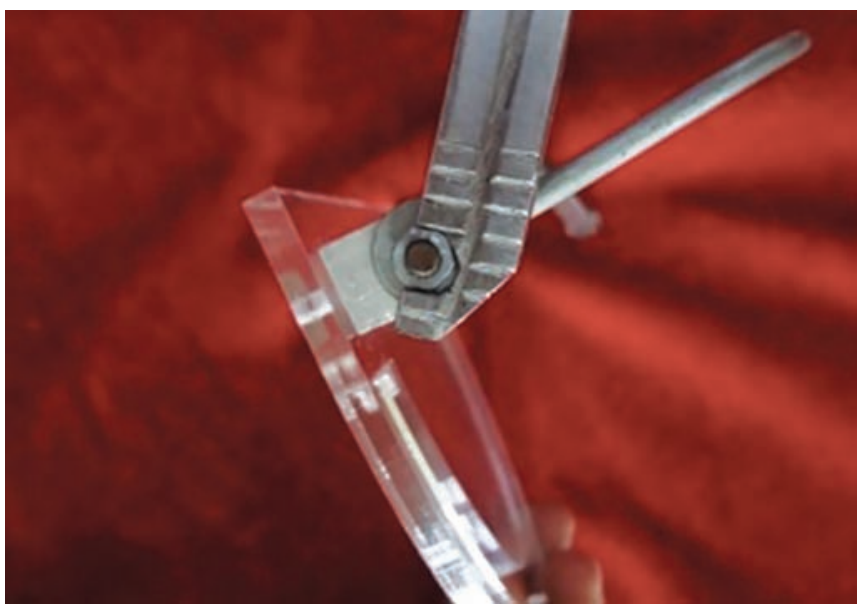

Fig. 3: Hex for controlling gauge analyser

Gauge analyzer (Fig. 1C): It is also "U" shaped and used to analyze gauge assembly at proper position to measure inclination of implant and adjacent tooth. It is $7 \mathrm{~mm}$ below the occlusal table to provide up and down free movement. It is made up of stainless steel wire to avoid corrosion and is $4 \mathrm{~mm}$ thick to provide strength.

Gauge assembly with pointer (Fig. 1D): Gauge assembly is used to measure angulations. It is also made up of stainless steel with $7 \mathrm{~mm}$ in height and $4 \mathrm{~mm}$ in width (Fig. 2). It has a pointer attached to it in the upper portion, and in the lower portion, it is attached with gauge analyzer. After its position is decided on the gauge analyzer, it has a provision for screw assembly that allows it to be stable at the same position. Pointer is attached with the gauge assembly by friction lock, and it is $7 \mathrm{~mm}$ in height because the least height of the clinical crown of first molar is $7 \mathrm{~mm}$.

Hex for controlling of gauge analyzer (Fig. 3): Position of gauge analyzer is decided and it is stabilized with the help of hex. It is also made up with stainless steel of $2 \mathrm{~mm}$ in thickness.

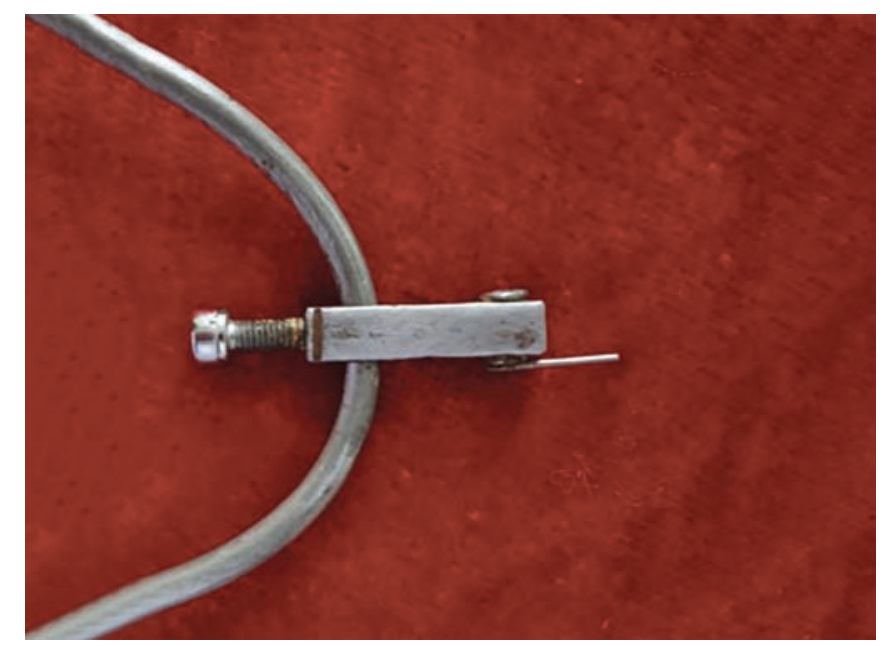

Fig. 2: Gauge analyser with pointer

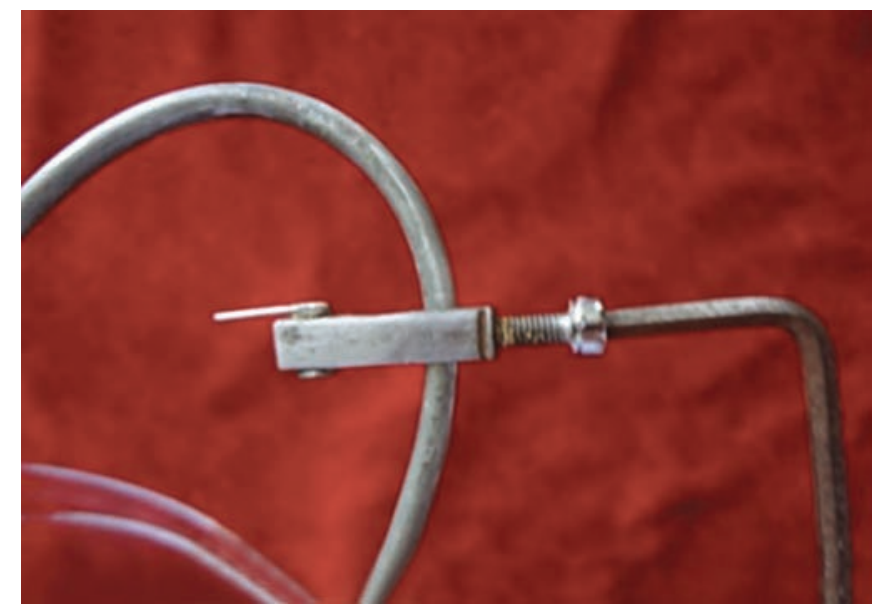

Fig. 4: Hex for controlling gauge assembly

Hex for controlling of gauge assembly (Fig. 4): Screw attachment provision given in the gauge assembly so as to tighten it at the same position.

Measuring protractor (Fig. 5): It is $3 \times 3 \mathrm{~cm}$ in dimension, as it is easy to measure angulations of small pointers. It has markings on it in different colors for every $5^{\circ}$, so that, it is easy to check angulations.

\section{DIFFERENT CLINICAL CONDITIONS AND STEPWISE METHOD TO USE THE INSTRUMENT}

\section{Single Tooth Missing (Anterior and Posterior)}

\section{Steps}

- Tripoding the cast

- Measure inclination of implant using tripoding marks, e.g., it is $75^{\circ}$ (Figs 6 and 7)

- Place the cast in the same position of tripoding marks, then measure inclination of adjacent tooth, e.g., it is $90^{\circ}$ (Fig. 8 ) 


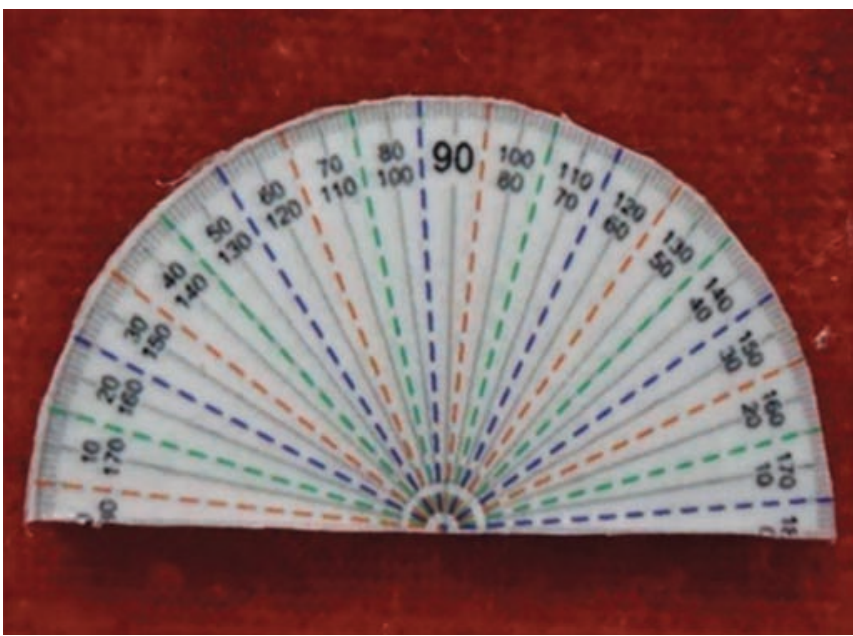

Fig. 5: Protractor with color markings at every $5^{\circ}$

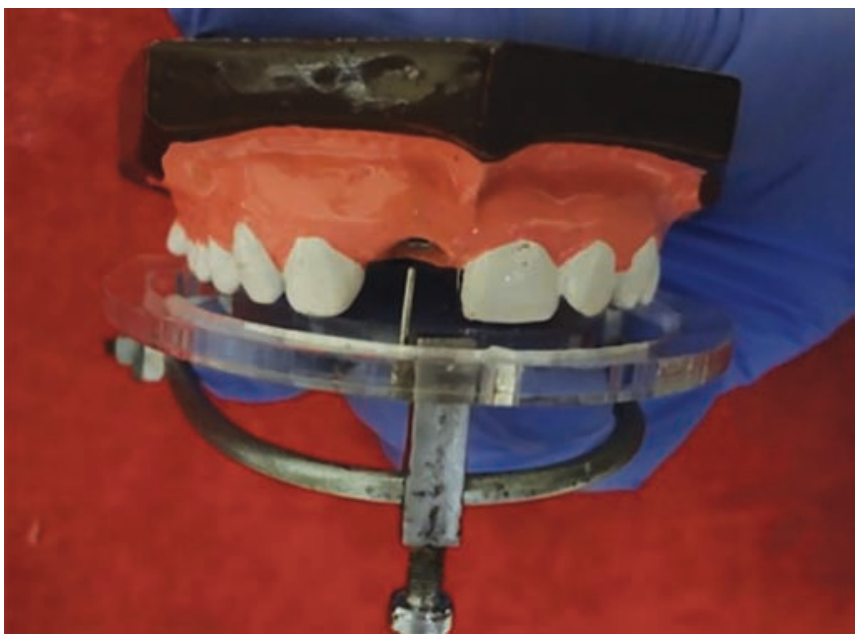

Fig. 7: Measuring angulation of the implant with the inclination gauge

- Calculate difference, e.g., it is $15^{\circ}$

- Degree of difference is the angulation for angled abutment (Fig. 9).

\section{Multiple Tooth Missing (Anterior and Posterior)}

\section{Steps}

- Make a removable partial denture in missing area, e.g., missing 11, 12, 13 (Fig. 10)

- Implant placement, e.g., in region of 11,13 and remove 11 and 13 in removable partial denture, so we can use 12 also as a guide along with the adjacent natural teeth (Figs 11 and 12)

- Tripoding the cast

- Measure inclination of implant using tripoding marks, e.g., $75^{\circ}$ (in region of 11 ), $80^{\circ}$ (in region of 13 )

- Measure inclination of adjacent tooth present using tripoding marks, e.g., $90^{\circ}$ (of 21) and $70^{\circ}$ (of 12). Calculate the difference, e.g., $15^{\circ}$ and $10^{\circ}$ of difference is the angulation for angled abutment.

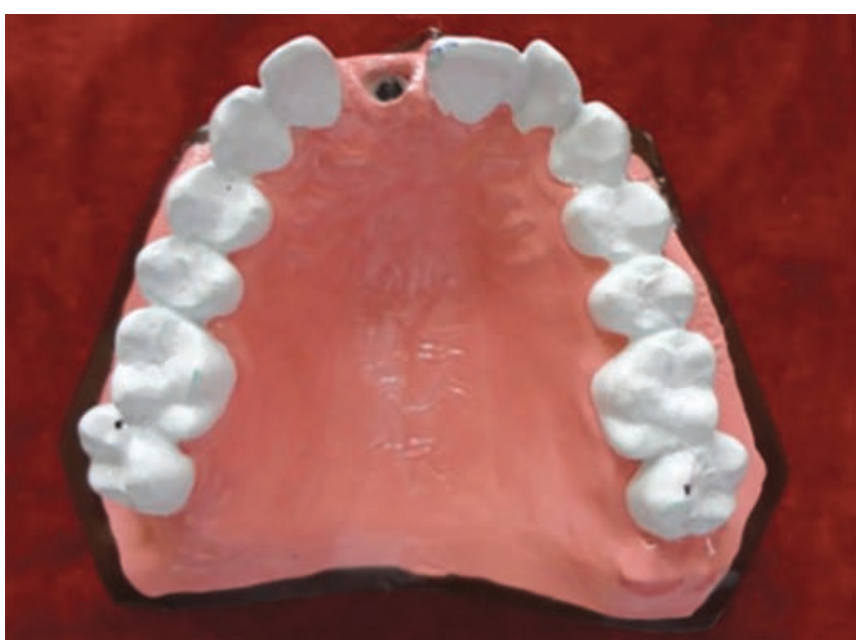

Fig. 6: Cast with the implant placed

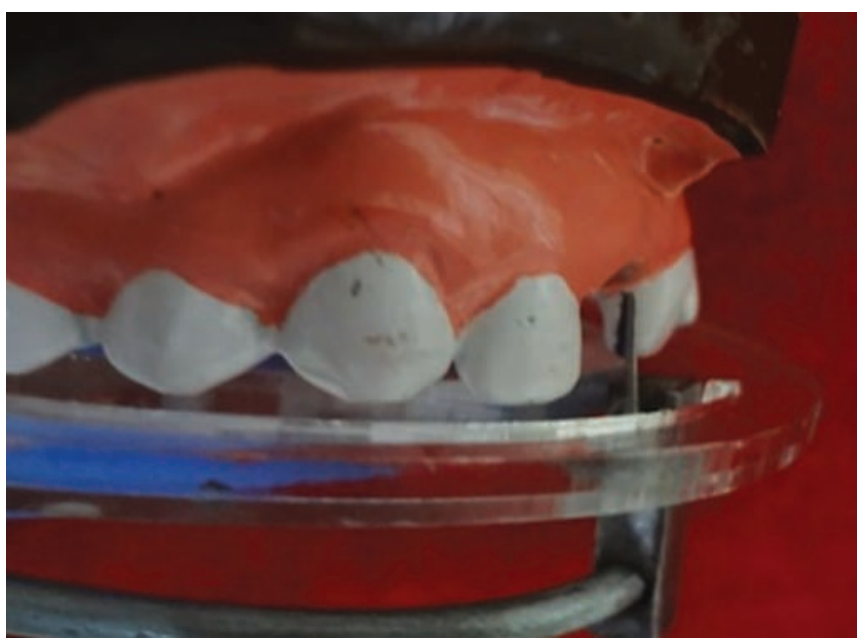

Fig. 8: Measurement of angulation of the adjacent tooth

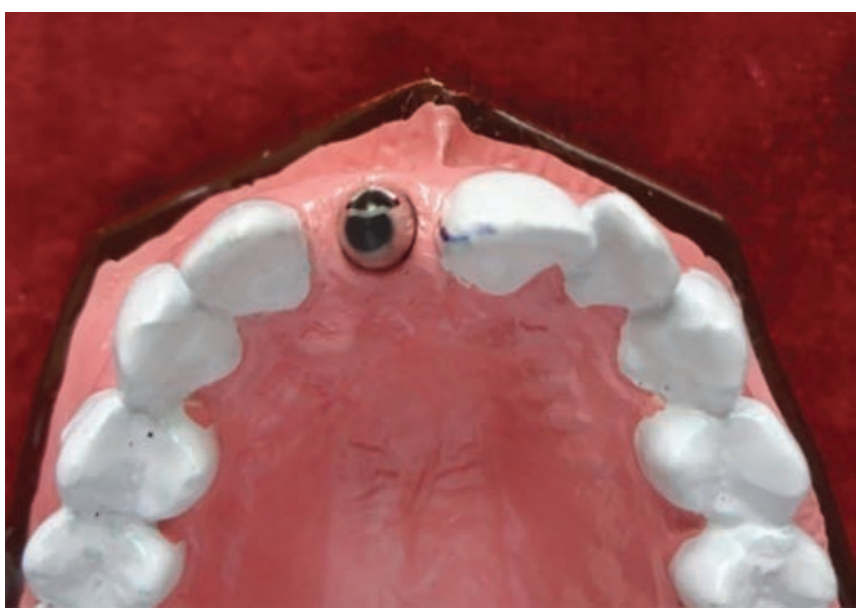

Fig. 9: Angled abutment placed

\section{Immediate Placement and Immediate Loading}

\section{Steps}

- Make a template for the tooth to be extracted

- Tripoding of the cast is done 


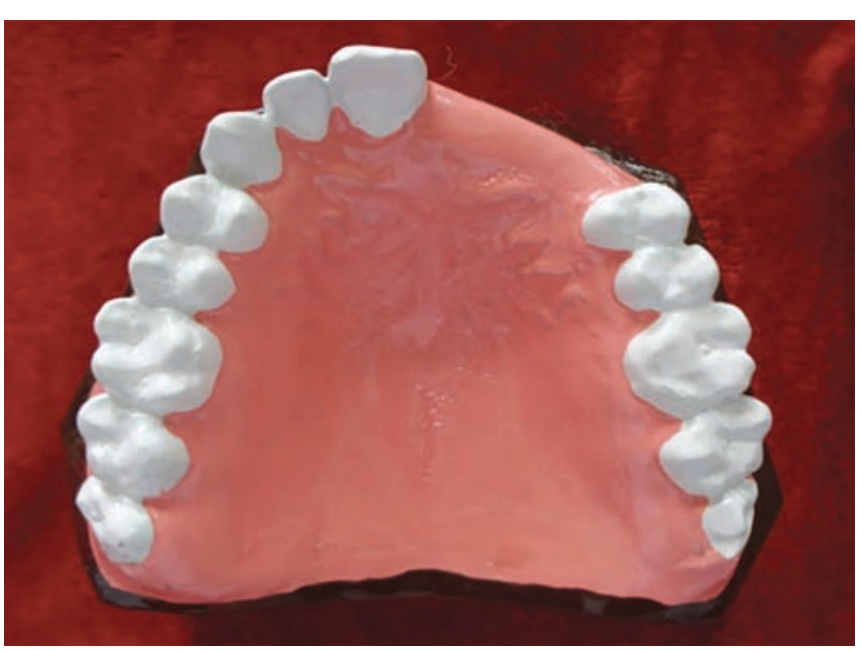

Fig. 10: Multiple teeth missing

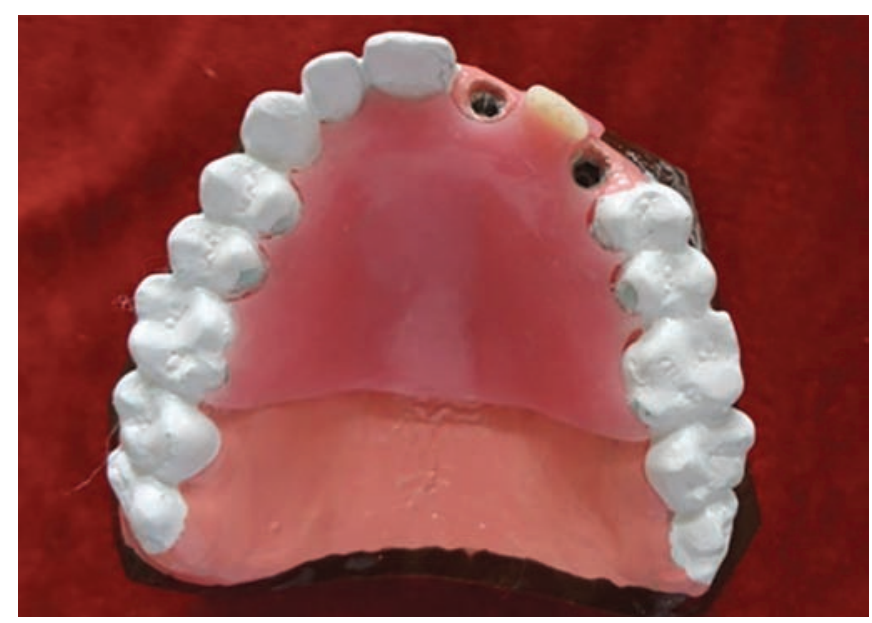

Fig. 12: Removable partial denture with 11 and 13 removed to measure the angulation of the implant and the adjacent teeth

- Measure inclination of implant by using template using tripoding marks, e.g., $65^{\circ}$

- Measure inclination of adjacent tooth using tripoding marks, e.g., $90^{\circ}$

- Calculate difference, e.g., $25^{\circ}$

- Degree of difference is the angulation for angled abutment.

\section{DISCUSSION}

Inclination gauge is useful to detect the proper angulation of abutment. Abutment angulation is detected by this instrument, which is not suitable for the physiological limits of bone. Then, reinsert implant with slightly larger dimension and change the implant direction. Clelland and Gilat2 assessed the effect of increasing abutment angulation on stress transfer to bone. They evaluated five abutment divergences $\left(0^{\circ}, 15^{\circ}, 25^{\circ}, 30^{\circ}\right.$, and $\left.35^{\circ}\right)$. They conducted these evaluations in a photoelastic resin and subjected individual, unsplinted implants to a 178 Newton load. The investigators used strain gauges to

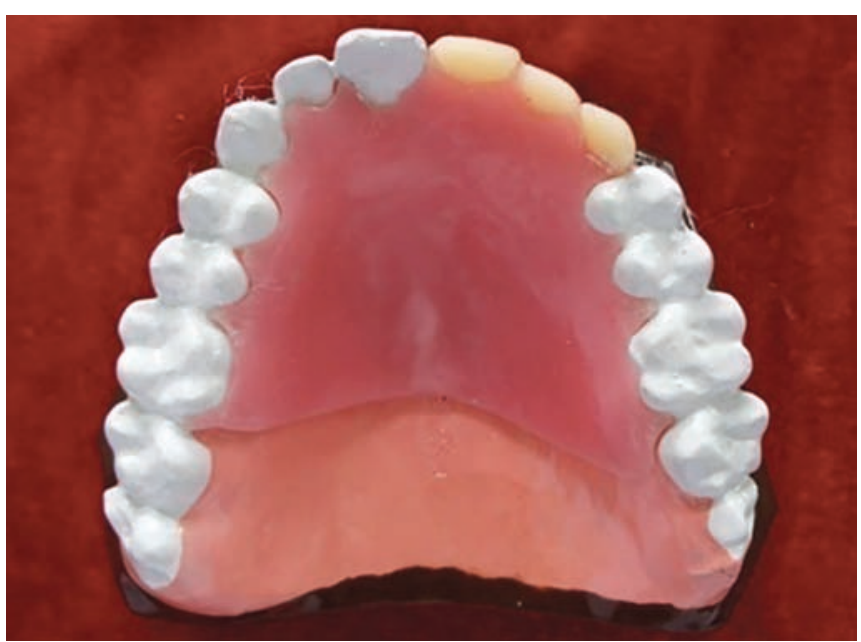

Fig. 11: Removable partial denture with missing teeth

confirm that compressive forces (in microstrains) became larger as abutment angulation increased: $0^{\circ}, 352 \mu$ strains; $15^{\circ}, 942 \mu$ strains; $25^{\circ}, 1126 \mu$ strains; $30^{\circ}, 1246 \mu$ strains; and $35^{\circ}, 1325$ ustrains. ${ }^{5}$

Martin and Burr indicated that the biological response of bone to compressive forces was ranked as follows:

- Physiological: 200 to 2500 ustrains

- Overload: 2500 to $4500 \mu$ strains

- Pathological: Greater than $4000 \mu_{\text {strains }}^{6}$

Hence, according to these standards till $35^{\circ}$, angulation forces are in physiological limits.

As early as 1990, Kallus et $\mathrm{al}^{2}$ demonstrated prototypeangled abutments of the Branemark (Nobel Biocare, Göteborg, Sweden) implant system. The advent of angled abutments has simplified the management of situations when implant placements are suboptimal. Gelb and Lazzara $^{7}$ presented three cases restored with preangled abutments to fulfill the esthetic demands and functional objectives of patients. Until the present time, no thorough review of the information on angled abutments can be found in the literature, which can elaborate both the efficacy and biomechanical mechanisms of this treatment modality.

Dentists understand the risks involved when restored prostheses are subjected to nonaxial loading. It has always been recommended to direct occlusal loads as close to the long axis of the fixture as possible. ${ }^{8}$

However, it is known that the loading on angled abutments is mostly off-axis, which raises the concern of how angled abutments generally perform with such an unfavorable loading regimen.

In one study, where implants placed in subhuman primates were loaded for 1 year, and there demonstrated that the quality of osseointegration was so excellent that overloading can only cause abutment screw breakage rather than loss of bone or failure of the implants. Using histological examinations, they found that "no osteoblasts 
or osteroclasts were present in the bone adjacent to the implants," leading them to the conclusion that no active remodeling had taken place. This finding is inconsistent with the theory that long-term implant interfaces can only be maintained through dynamic modeling and remodeling processes. ${ }^{9}$ This should apply to angled abutments as well. Other types of failure related to angled abutments in reviewed articles included fracture of the occlusal material, fracture in parts of the framework, ${ }^{10}$ loosening or fracture of abutment screws, and loss of osseointegration. ${ }^{11}$ Balshi et $\mathrm{al}^{10}$ conducted a 3-year study of 71 fixed prostheses. They used angled abutments $\left(30^{\circ}\right)$ or a combination of angled and standard abutments to support prostheses. They inserted 209 angled (test) abutments and 212 standard (control) abutments to support fixed prostheses. The survival rates for the maxillary control group and test implants were 91.3 and $94.8 \%$ respectively; in the mandible, the survival rates were $97.4 \%$ for the control group and $94.1 \%$ for the test group respectively. With respect to fixed prostheses followed for up to 3 years, the survival rate was $96.8 \%$ in the maxilla and $100 \%$ in the mandible. The most tapered preangled abutment reviewed was $45^{\circ}$. It was stated that the magnitude of the angle did not influence the survival rate. ${ }^{12}$ However, three-dimensional finite element data showed that $45^{\circ}$ angle of loads on an implant tripled the compressive stress. ${ }^{13}$ They also increased tensile stresses from almost 0 to 4000 psi in the bone. No other in vitro stress/strain data were found for such an extreme angle. Clinical application of angled abutments with such angulation should be used with great caution before the scientific evidence approves its feasibility.

Most of the articles claiming high success/survival rates did not take abutment screw loosening, occlusal material, or framework fracture into account in calculating the success / survival rates. These complications might not eventually lead to implant failure, but can still frustrate both dentists and patients and should be major concerns from a biomechanical point of view. Careful examination and documentation of such events to be included in future success/survival analyzes are essential.

\section{CONCLUSION}

Based on the available data in the literature, we can draw several conclusions. Angled abutments result in increased stress on the implants and adjacent bone. These increased stresses usually are within physiological tolerances. Based on the limited clinical trials reported in the literature and the authors' clinical experience, we believe it is acceptable to use angled abutments of proper angulations to achieve parallelism between implants or adjacent structures. It is possible with this instrument to maintain stresses within physiological tolerances of bone.

\section{REFERENCES}

1. Ten Bruggenkate CM, Sutter F, Oosterbeek HS, Schroeder A. Indications for angled implants. J Prosthet Dent 1992 Jan;67(1): 85-93.

2. Kallus T, Henry P, Jemt T, Jorneus L. Clinical evaluation of angulated abutments for the Branemark system: a pilot study. Int J Oral Maxillofac Implants 1990 Spring;5(1):39-45.

3. Clelland NL, Gilat A. The effect of abutment angulation on stress transfer for an implant. J Prosthodont 1992 Sep;1(1):24-28.

4. Cavallaro J Jr, Greenstein G. Angled implant abutments: a practical application of available knowledge. J Am Dent Assoc 2011 Feb;142(2):150-158.

5. Clelland NL, Lee JK, Bimbenet OC, Brantley WA. A three dimensional finite element stress analysis of angled abutments for an implant placed in the anterior maxilla. J Prosthodont 1995 Jun;4(2):95-100.

6. Martin, RB.; Burr, DB. Skeletal radiology. In: Martin RB, Burr DB, editors. Structure, function, and adaptation of compact bone. New York: Raven Press; 1989. p. 143-185.

7. Gelb DA, Lazzara RJ. Hierarchy of objectives in implant placement to maximize esthetics: use of pre-angulated abutments. Int J Periodontics Restorative Dent 1993 Jun;13(3):277-287.

8. Barbier L, Vander Sloten J, Krzesinski G, Schepers E, Van der Perre G. Finite element analysis of non-axial versus axial oral implants in the mandible of the dog. J Oral Rehabil 1998 Nov;25(11):847-858.

9. Stanford CM, Brand RA. Toward an understanding of implant occlusion and strain adaptive bone modeling and remodeling. J Prosthet Dent 1999 May;81(5):553-561.

10. Balshi TJ, Ekfeldt A, Stenberg T, Vrielinck L. Three-year evaluation of Branemark implants connected to angulated abutments. Int J Oral Maxillofac Implants 1997 Jan-Feb;12(1):52-58.

11. Eger DE, Gunsolley JC, Feldman S. Comparison of angled and standard abutments and their effect on clinical outcomes: a preliminary report. Int J Oral Maxillofac Implants 2000 Nov-Dec;15(6):819-823.

12. Sethi A, Kaus T, Sochor P. The use of angulated abutments in implant dentistry: five-year clinical results of an ongoing prospective study. Int J Oral Maxillofac Implants 2000 Nov-Dec;15(6):801-810.

13. Misch, C. Occlusal considerations for implant-supported prostheses. In: Rupoldh P, editor. Contemporary implant dentistry. 2nd ed. St. Louis: Mosby; 1999. p. 609-628. 